\title{
Factors Influencing the Adoption of Treated Wastewater Use Among Communities in Ruai, Nairobi County, Kenya
}

\author{
Gerald Irungu Maina $^{1 *} \quad$ Andrew Wekesa Wamukota $^{1} \quad$ Maarifa Ali Mwakumanya $^{2}$ \\ 1.Department of Environmental Studies (Community Development), Pwani University, P.O. Box 195- 80108, \\ Kilifi, Kenya \\ 2.Department of Environmental Science, Pwani University, P.O. Box 195- 80108, Kilifi, Kenya \\ *Corresponding Author. Email: g.irungu@pu.ac.ke
}

The research is self-sponsored

Abstract

The Dandora Estate Sewage Treatment Works (DESTW) in Ruai, Nairobi County discharges approximately $80,000 \mathrm{~m}^{3} /$ day of treated wastewater (TWW) into the Nairobi River without any planned option for use. There is also no policy guideline for use of TWW in Kenya. Yet, some people still use it directly or indirectly for their various livelihoods and in unsustainable ways (unplanned, unmanaged and unregulated). This could result in a number of risks, including public health, agronomic and environmental risks. This study investigated factors influencing the adoption of the TWW use among the communities in seven estates (Sewage/IDP, Gituamba, Kamunyonge, Katworo, Bondeni, Dan Bull and By-pass) that are close to the DESTW, despite the prevailing scenario. Cross-sectional survey design was adopted in the study where semi-structured questionnaires were used to collect data from 360 households who were selected using simple random sampling from the seven estates/strata. Raw data were analysed with the help of Statistical Package for Social Sciences [version 20] software for both descriptive statistics (percentages and frequencies) and inferential statistics (Odds Ratio, and Wald $\chi^{2}$ ) for the prediction of adoption of TWW (dependent variable) using the independent variables. A multivariate logistic regression model identified gender (Wald $\left.\chi^{2}(1)=5.31, p=.021\right)$, main occupation in general $\left(\right.$ Wald $\chi^{2}(7)=21.06$, $p=.004$ ), farming [Wald $\chi^{2}(1)=5.31, p=.021$ ], dependency on wastewater (Wald $\left.\chi^{2}(1)=40.59, p<.000\right)$ and knowledge of organization regulating use of TWW (Wald $\chi^{2}(2)=6.76, p=.034$ ) as statistically significant predictors of adoption of TWW use in Ruai. In the absence of a policy guideline for use of TWW in Kenya, the findings of the study provide requisite baseline data useful in formulating an appropriate policy and regulations for wastewater reuse schemes.

Keywords: Adoption, Treated wastewater (TWW), livelihoods, Predictors, Logistic regression

DOI: $10.7176 / \mathrm{JEES} / 10-6-07$

Publication date:June $30^{\text {th }} 2020$

\section{Introduction}

1.1 Background

Water is a key resource in most human livelihoods (Buechler, 2004) around the world in a variety of socioeconomic sectors including agriculture, mining, commercial fisheries, recreation and tourism, power generation, forest generation, industries and biotechnology/pharmaceuticals (Kabul, 2011; Winpenny, Heinz and KooOshima, 2010). Pressure on water resources from the continuing population growth and urbanization, rapid industrialization, expanding and intensifying food production threaten fresh water supplies globally (Corcoran, et al., 2010). Moreover, freshwater is a scarce resource, especially, in many semi-arid and arid regions of the world, (Khalil and Kakar, 2011; Mekala, et al., 2008; Buechler, 2004). This scenario, exacerbated by frequent droughts, decreasing and irregular rainfall patterns over the years (Mekala et al., 2008), threatens economic development, sustainable human livelihoods, environmental quality, and a host of other societal goals in countries and regions around the world (Omran, 2011). Hence, the need to look for alternative water resources has become imperative (Mekala et al., 2008).

One such alternative which is regarded worldwide is wastewater (Mahjoub, Mekada and Gharbi, 2016). It is often available near urban centres year-round in sufficient quantities unlike freshwater from rainfall which is concentrated in the often short and sporadic rainy season (Buechler, Mekala and Keraita, 2006). As urban populations in developing countries increase, and residents seek better living standards, larger amounts of freshwater are diverted to domestic, commercial, and industrial sectors, which generate greater volumes of wastewater (Qadir, et al., (2010). Wastewater which is about 99 per cent water and only one per cent solid wastes (Vigneswaran and Sundaravadivel, 2004) is simply too valuable to waste (Mara, 2001) and is gaining recognition as a valuable water resource around the world (Scheierling, et al. 2010; Vedachalam and Mancl, 2010; Carr and Potter, 2013; Keremane and Mckay, 2006).

The concept of beneficial use of treated wastewater - mainly due to the absence of a suitable alternative water resource, its high nutrient value beneficial for crop production, reliability and its proximity to urban markets (Khalil et al., 2011; Mara, 2001; United Nations World Water Assessment Programme (WWAP), 2017) issues of 
climate change, increases in urban population and increased demand for water from competing sectors (Mekala et al, 2008) - has rapidly become imperative for water agencies around the world (Po, Kaercher, and Nancarrow, 2003). Its use is becoming an important strategy to complement the existing water resources for both developing and developed countries and there are lessons, experiences, data and technology that can be shared for mutual benefit (Mekala et al, 2008). In this regard, several arid countries have developed water security strategies where wastewater reuse is a major component (Amare, et al., 2017; Shomar and Dare, 2015). TWW has been considered as a viable source of water for several decades in several developed countries in Europe, USA, Japan, and others (Shomar and Dare, 2015). In most of the countries of the Mediterranean region, (Cyprus, Israel, Jordan, and Tunisia, France) wastewater is widely reused at different extents within planned or unplanned systems (Kumar, 2014) as a source of crop nutrients over many decades (Jiménez et al, 2010).

Kenya operates the second biggest wastewater treatment plant in Africa - the Dandora Estate Sewage Treatment Works (DESTW) in Ruai run by the Nairobi City Water and Sewerage Company (NCWSC) - using Waste Stabilization Ponds (WSP) technology (Mireri et al., 2007). DESTW treats about $80,0000 \mathrm{~m}^{3} /$ day equivalent to about $80 \%$ of Nairobi's wastewater generated. All this effluent is discharged into the adjacent Nairobi River (NCWSC, 2015) with no reuse option. Wastewater reuse has not been adopted, neither recognized by the existing guidelines/laws in Kenya (Opaa and Omondi, 2012; Kaluli et al., 2011). Yet TWW from a WSP is considered as a valuable resource for reuse by water resources managers (Almas and Scholz, 2006). Nevertheless some people neighbouring the treatment plant use it directly or indirectly for various activities in unsustainable ways (i.e. unplanned, unmanaged and unregulated). This could result in a number of risks, including public health, sanitation challenges, agronomic, and environmental risks (Scheierling et al., 2010). The factors influencing this adoption of TWW use despite the gloom scenario have remained unknown and undocumented, a gap that this study was designed to fill.

\subsection{Objective and Hypothesis of the Study}

The specific objective of the study was to investigate the factors influencing the adoption of TWW use among communities in Ruai. To help achieve this objective the study sought to answer the following questions:

I. What percentage of the population has adopted the use of TWW in Ruai?

II. What are the demographic and non-demographic factors among the household in Ruai in relation to adoption of TWW use?

III. Which of these factors statistically influence the adoption of TWW use in Ruai?

Given the objective of the study, the following hypothesis is spelt out:

$H_{o}$ : There is no significant factor influencing the adoption of TWW use among communities in Ruai.

\subsection{Factors Influencing the Adoption of TWW use}

According to Po, Kaercher and Nancarrow (2003) the driving forces behind the introduction of water reuse in Australia include: public perceptions, acceptance of water reuse, droughts and prediction of possible further droughts from climate change, meeting the needs of a growing population, demand from the general community to have greener water strategies and water conservation, increased industrial and agricultural needs, to allow conservation of higher quality water for suitable uses, heightened awareness of the potential benefits of using recycled water in the agricultural industry, and more advanced wastewater treatment processes.

Other factors include public opposition resulting from a combination of prejudicial beliefs, fear, attitudes, lack of knowledge and general distrust of public utilities (Vedachalam and Mancl, 2010) culture, religion, available technology and politics (Kellis, Kalavrouziotis and Gikas, 2013), lack of job opportunities especially where water reuse represents the only possibility of improving living standards by increasing income and ensuring food supplies (Jiménez, 2006). According to Angatia (2013), various variables including water availability, institutional arrangement, financial resources and developmental planning can influence wastewater management and reuse.

The public's awareness on sustainable water resources management is essential (Asano and Bahri, 2011) in influencing the participant's knowledge, attitude and perceptions regarding benefit and health risks associated with wastewater reuse (Njagi, 2013). Educating the public is one of the most important aspects of wastewater management because most people may not think about wastewater, where it goes or the complexities involved in providing wastewater services to prevent the spread of disease (GEF Caribbean Regional Fund for Wastewater Management Project (GEF CReW), 2015). Besides, awareness raising and promotion of reuse practices encourage active participation of NGOs and local communities in the supply chain of wastewater reuse (IWA, 2018). Hence, as reported in Keremane and Mckay (2006), awareness programmes regarding the legal, social, economic, and environmental and health issues related to wastewater should target all key stakeholders.

Risks associated with the use of wastewater could also influence adoption of TWW use. While the use of wastewater especially in agriculture has positive effects for farmers, mainly related to its contribution to their income, it also has negative effects on human health (especially when used untreated), sanitation challenges, agronomic, and environmental risks (Jiménez, 2006; Weldesilassie et al., 2009, Scheierling et al., 2010). As Po et 
al., (2003) reported, perception of risk associated with using recycled water may influence the behavioral acceptability of a reuse scheme to the general community and the closer the recycled water is to human contact or ingestion, the more people are opposed to using the water.

\section{Methodology}

\subsection{Study Area}

This study was carried out in Ruai sub-location, Embakasi Sub County in Nairobi East which is about $20 \mathrm{~km}$ from the city centre (Figure 1). It lies between latitudes $1^{0} 22^{\prime} 88^{\prime \prime} \mathrm{S}$ and $1^{0} 29^{\prime} 89^{\prime \prime} \mathrm{S}$ and longitudes $36^{\circ} 94^{\prime} 32^{\prime \prime} \mathrm{E}$ and $37^{\circ} 04^{\prime} 49^{\prime \prime}$ E. Ruai is connected to City Centre through Kangundo, Outering and Jogoo roads (Sigoria, 2012). It covers an area of 49.0 sq. kilometres with a population density of 540, a total population of 26,448 and 7316 households (Kenya National Bureau of Statistics (KNBS), 2009).

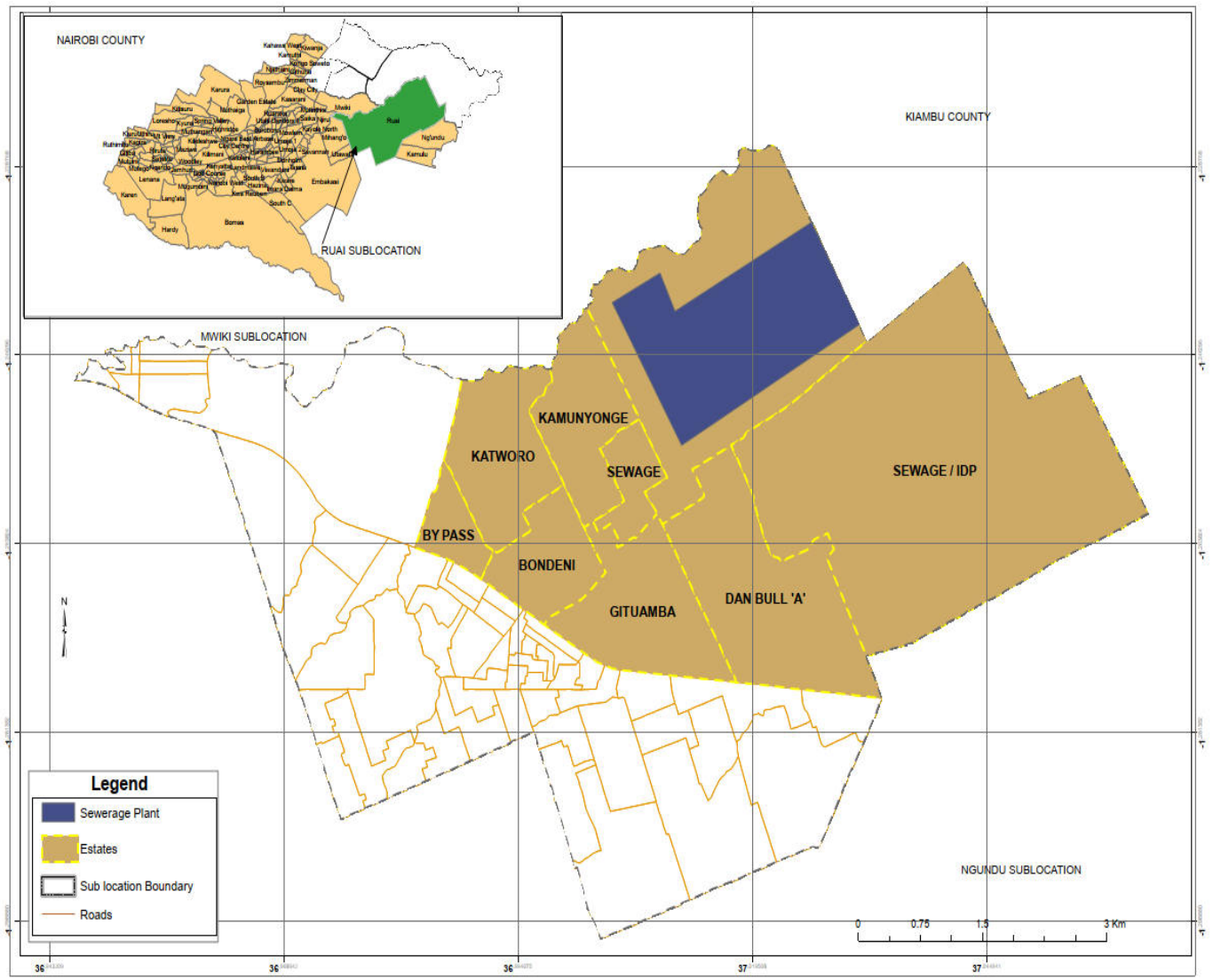

Figure 1: Map of the Study Area [Source: Author]

Note. Area shaded brown shows the selected estates in Ruai sub location where social data were collected.

\subsection{Research Design}

The study used a descriptive cross-sectional design. Cross-sectional survey is most commonly used in social sciences and best suited to studies aimed at finding out the prevalence of a phenomena or situation (Kumar, 2011). This approach was used to collect social data on the demographic and non-demographic characteristics of households' respondents using semi-structured questionnaires.

\subsection{Target Population}

The target population for the study comprised households in seven estates (Figure $1 \&$ Table 1) that are close to and falling within an approximately four kilometres radius 4 from DESTW, where treated wastewater is produced and hence can be used economically as stated in WWAP (2017). Sewage and Sewage/IDP estates were treated as one estate because of the similarity of names. The total number of households in these estates was 3261 (Kenya National Bureau of Statistics [KNBS], 2009).

\subsection{Sample size}

The study used the following formula to get the sample size of households as recommended in (Kothari, 2004) 
and Bartlett et al., 2001(as cited in Taherdoost, (2017):

$$
n=\frac{Z^{2} \cdot p \cdot q \cdot N}{e^{2}(N-1)+Z^{2} \cdot p \cdot q}, \quad \text { For finite population }(\mathrm{N}) \text {. }
$$

Where:

- $\quad \mathrm{N}$ is the target population which is known.

- $\mathrm{n}$ is the desired sample size, 3261 in this study.

- $\mathrm{Z}$ is the statistical value corresponding to the level of confidence required of $95 \%$ (or 0.95 ) which is 1.96

- $\mathrm{P}$ is the proportion of the target population estimated to have the characteristic being measured. According to Mugenda and Mugenda (2003), "if there is no estimate available of the proportion in the target population assumed to have the characteristics of interest, $50 \%$ should be used". This will result in the maximization of variance and produce the maximum sample size as described in Bartlett et al., 2001(as cited in Taherdoost, 2017).

- $\mathrm{q}=1-\mathrm{p}$

- $\mathrm{e}^{2}$ is the level of significance set (for this study, it is 0.05 level).

Hence, the sample size (household respondents) for the study was calculated thus:

$\mathrm{n}=\left[(1.96)^{2} * 0.5 * 0.5 * 3261\right] /\left[(0.05)^{2}(3261-1)+(1.96)^{2} * 0.5 * 0.5=344\right.$

The formula gave 344 as the minimum number of households that should be used in this study. A higher sample size of 360 was considered in the study to cater for non-responses which is an approach used in other similar social studies (Wemali, 2014; Mburu, 2016). One individual in each household, preferably the household head was selected as the respondent.

\subsection{Sampling Procedures}

The targeted population was stratified into the seven estates as aforementioned. All the households in the strata became potential units of observation. The sample size of the households in each stratum was then worked out proportional to the total number of households in the stratum (Table 1). Then from each stratum simple random sampling was used to select the households from which the household heads or their representatives became the respondents. This method is an easier and less costly method of sampling and can be conveniently used even in cases of large populations and would reduce bias (Kothari, 2004). To facilitate the selection of households, the researcher conducted a reconnaissance visit to familiarize with the study area and consulted with the estates social/community leaders locally known as wazee wa nyumba kumi. A topographical map of the area showing the roads network was also used. A research assistant and one member of the 'Nyumba Kumi' officials of the estates, helped to map out the households in each estate.

Table 1: Households Size and Samples in the Selected Estates

\begin{tabular}{|c|c|c|c|c|c|c|}
\hline S/no & Estate / Stratum & $\begin{array}{l}\text { Total number } \\
\text { households }\end{array}$ & of & $\begin{array}{l}\text { Proportion } \\
(\%)\end{array}$ & $\begin{array}{l}\text { Sample } \\
\text { size }\end{array}$ & $\begin{array}{l}\text { Response rate } \\
(*)\end{array}$ \\
\hline 1 & Kamunyonge & 504 & & 0.15 & 56 & $56(100)$ \\
\hline 2 & Gituamba & 667 & & 0.20 & 74 & $74(100)$ \\
\hline 3 & Katworo & 359 & & 0.11 & 40 & $40(100)$ \\
\hline \multirow[t]{2}{*}{4} & Sewage & & & & & \\
\hline & IDP/Sewage & 606 & & 0.19 & 67 & $67(100)$ \\
\hline 5 & Bondeni & 687 & & 0.21 & 75 & $72(96.0)$ \\
\hline 6 & Dan Bull & 247 & & 0.08 & 27 & $25(92.6)$ \\
\hline \multirow[t]{2}{*}{7} & Bypass & 191 & & 0.06 & 21 & $20(95.2)$ \\
\hline & Total & 3261 & & 1.00 & 360 & $354(98.3)$ \\
\hline
\end{tabular}

Note. IDP stands for internally displaced persons, $(*)=$ response rate in percentage.

Source: Adapted from Kenya National Bureau of Statistics 2009 Census

\subsection{Data Collection Instruments}

Semi-structured questionnaires were developed and used to collect data from the households respondents on their demography including gender, marital status, age, level of education, home ownership, main occupations and their non-demographic factors such as perception of TWW, knowledge of use of TWW, support the use of TWW, reasons for use of TWW, willingness to use TWW, awareness of the benefit and risks associated with the use of TWW, regulations for the use of TWW, permission to use TWW, and dependency on TWW for livelihoods.

\subsection{Data Collection Procedures}

A research assistant was trained prior to the main study and helped to collect the social data from the households' respondents. During the actual fieldwork study face to face administration of the questionnaire were conducted with the household's respondents. The research team built rapport with the respondents and ensured confidentiality 
and anonymity on the part of the respondent's information. This was enhanced by providing a preamble in the questionnaire schedule highlighting the sole purpose of the study and requesting the respondents to feel free to give accurate information without disclosing their identities on the questionnaire schedules provided. Following the respondent's acceptance to participate, the data were collected and entered in the questionnaire by either the researcher and/or his assistant. However, those respondents that requested to fill the questionnaire by themselves were allowed to do so. This facilitated a wide range of coverage of households at their convenience and alleviated any pressures on respondents' time in the participation in the questionnaire administration.

\subsection{Data Analysis}

Raw data were cleaned, harmonized, coded and stored in Microsoft Excel as spreadsheet database. Analyses were conducted using both the Ms Excel and the SPSS (IBM SPSS Statistics for Windows, Version 20.0) software. Descriptives such as frequencies, percentages were done. For Inferential statistics, a binary logistic regression analysis was employed to predict the probability that a respondent would adopt the use of TWW. The predictor variables were respondents' demography including; gender, marital status, education level, main occupation, and non-demographic data including; perception of TWW as a valuable resource for livelihoods, support of use of TWW, knowledge of use of TWW, lack of alternative water source, TWW is accessible, TWW is reliable, TWW is rich in nutrients, TWW is used for income, willingness to use TWW, dependency on wastewater, permission to use TWW, knowledge of organization regulating use of TWW, organization effectiveness, and public awareness on benefit and risk associated with the use of TWW. Both univariate and multivariate logistic regression were carried out. Univariate analysis helps in screening for significant variables as described in Burns and Burns, (2008) and Bursac, et al., (2008). All statistical tests were conducted at a 0.05 level of significance.

A binary logistic regression analysis is done to assess the relationship between the hypothesized influencing factors (independent variables also referred to as predictors in the study) and the adoption of TWW use (a dichotomous dependent variable) as described in Hyeoun-Ae, (2013). "Logistic regression model corresponds to data from a cross-sectional..." study as noted in Hsieh, et al., 1998 (as cited in Hyeoun-Ae, (2013, p.157) and is well suited for describing and testing hypotheses about relationships between a categorical outcome variable and one or more categorical or continuous predictor variables (Peng, Lee and Ingersoll, 2002; Salkind, 2007). Logistic regression is unique in that it allows one to predict the probability of occurrence of an event (nominal variable), unlike other techniques such as one-way ANOVA and linear regression (Mauša, Grbac and Bašić, 2012; McDonald, 2014). The independent variables are fitted to a logistic function where the output can take on values between zero and one. It is suitable because there are only two possible outcomes: either the respondent is using/has ever used TWW or not. It also offers more flexibility and robustness. It does not assume linear relationship between the input and output variables, nor normal distribution and equal variance within input variables and homoscedasticity of the errors unlike the ordinary least squares (OLS) regression or linear discriminant function analysis (Mauša, et al., 2012; Peng, et al., 2002; Hyeoun-Ae, 2013).

According to Pourhoseingholi, et al., (2012) logistic regression also acts as a control technique for numerous confounders by giving an odds ratio (OR) which is controlled for multiple confounders. Odds ratio which is a comparative measure of two odds relative to different events (Hyeoun-Ae, 2013) is used to assess the isolated impact of each independent variable on the dependent variable as described in Burns and Burns, (2008). Odds ratio as a measure of effect size is the ratio of relative importance of the independent variables in terms of effect on the dependent variables (Pourhoseingholi, et al., 2012).

To get the best predicting performance, where predictors not related to the outcome and whose inclusion may degrade the performance of the model are systematically eliminated, the study adopted a stepwise selection procedure as described in Mauša et al., (2012). This practice also reduces chances of obtaining numerically unstable estimates and large standard errors (Bursac, et al., 2008).

A stepwise method almost always resolves multicollinearity with SPSS inspecting which predictors really contribute to predicting the dependent variable and excluding those who don't. A backward stepwise method was preferred with the criteria of $p \geq 0.10$ for removal of the covariate from the model. This is because, unlike the forward stepwise method, the procedure starts with a model that includes all the independent variables and, one at a time is to be removed from the model, until a stopping criterion is fulfilled as described in (Kandler, et al., 2015; Mauša et al, 2012; IBM corporation, 2011; Norušis, 2008), leading to a parsimonious model and results that are numerically stable and generalizable (Bursac, et al., 2008; Mauša et al, 2012). Backward method also shows better result compared to forward method of stepwise regression analysis (Jamil, et al., 2018). Overall, a Wald $\chi^{2}$ - test statistic is used to determine the $p$ value indicating whether a certain predictor is significant or not in the logistic regression model.

A univariate analysis of each variable was carried out whereby any variable having a significant univariate test based on the Wald $\chi^{2}$ test from logistic regression and a $p$-value cut-off point of 0.5 was selected as a candidate for the multivariate analysis as described in Bursac, et al., (2008). Any independent variables (predictors) whose effect on the prediction by the model was insignificant ( $\mathrm{p} \geq .05$ ) was dropped (Burns and Burns, 2008). 
2.8.1 The logistic regression equation

The logistic regression calculates the probability of occurrence of an event and explains the impact of the independent variables in terms of odds as described in (Hyeoun-Ae, 2013). An odds of an event is the ratio of the probability that the adoption of TWW use will occur to the probability that it will not occur. If the probability of adoption occurring is $p$, the probability of the event not occurring is $(1-p)$. Then the corresponding odds is a value given by:

Odds of $\{$ Event $\}=\left(\frac{p}{1-p}\right)$

Logistic regression gives each predictor a coefficient ' $b$ ' which measures its independent contribution to variations in the adoption of wastewater (dependent variable). The dependent variable can only take on one of the two values; 0 or 1 . Therefore, the outcome of the regression is not a prediction of a $Y$ value, as in linear regression, but a probability of belonging to one of two conditions of $Y$.

The natural log odds as a linear function of the explanatory variable is modelled as described in Burns and Burns, (2008) and Hyeoun-Ae, (2013), thus:

Logit $(y)=\log \left(\frac{p}{1-p}\right)=\ln \left(\frac{p}{1-p}\right)=\mathrm{a}+\mathrm{b} \chi$

Where $p$ is the probability of adopting the use of TWW $(y)$ (coded 1), 1-p is the probability of not adopting TWW use (coded 0 ), and $x$ is the explanatory variable, whereas $a$ and $b$ are the parameters of the logistic regression.

Taking the antilog of equation (2) on both sides, one can derive an equation for the prediction of the probability of the occurrence of interested outcome (Hyeoun-Ae, 2013) as:

$p=\frac{e^{\mathrm{a}+\mathrm{bx}}}{1+e^{\mathrm{a}+\mathrm{bx}}}$

Extending the logic of the simple logistic regression to multiple predictors, one may construct a complex logistic regression as:

Logit $(y)=\log \left(\frac{p}{1-p}\right)=\ln \left(\frac{p}{1-p}\right)=\mathrm{a}+\mathrm{b} 1 \chi 1+\ldots+\mathrm{bk} \chi \mathrm{k}$

Therefore, the probability of the occurrence of adoption of TWW use becomes:

$p=\frac{e^{a+b 1 \times 1+b 2 \times 2+\cdots}}{1+e^{a+b 1 \times 1+b 2 \times 2+\cdots}}$

Where:

$p=$ the probability that a case is in a particular category (adopted TWW use),

$e=$ the base of natural logarithms (approx 2.72),

$a=$ the constant $/$ intercept of the equation and,

$b_{1 \text { to } k}=$ coefficients for $k$ predictors $X_{I}$ to $X_{k}$, (Hyeoun-Ae, 2013).

\subsubsection{Evaluations of the Logistic Regression Model}

As described in Peng et al., (2002) and Hyeoun-Ae, (2013), the evaluation of the final logistic regression model obtained in the study was done by a) conducting statistical tests of individual predictors to assess their importance [univariate logistic analysis], b) assessing the overall model [i.e. multivariate logistic analysis for the relationship between the independent variables and dependent variable], c) goodness-of-fit statistics which involved carrying out the Hosmer-lemeshow and Omnibus tests. The likelihood test and the resulting values for Pseudo $\mathrm{R}^{2}$ for the final model were also integrated in this section and d) evaluating the predictive accuracy of the model which was given in terms of the sensitivity, specificity, false positive and false negative of the final model.

\section{Results and Discussion}

3.1 Status of Adoption of TWW Use by Household respondents in Ruai

Figure 2 shows that $228(64.4 \%)$ of the respondents were non-adopters of the use of treated wastewater for their livelihoods in Ruai as opposed to $126(35.6 \%)$ who adopted. This finding is similar to that of a study done in China which reported that a not-high level of wastewater reuse on the whole despite having a huge potentiality of its reuse (Lyu, et al., 2016). A household was considered to have adopted the use of treated wastewater if it is using or has ever used TWW for their livelihoods in Ruai at any one particular time. There was a strong positive relationship between respondents' adoption status and the estate they come from with a $\left[\chi^{2}(6)=93.2, p<.000\right.$; $V=.513]$. More respondents residing in estates that were closest to DESTW (the source of TWW) such as Sewage/IDP and Dan Bull were adopters than non-adopters. This indicated that the shorter the distance of a source of a resource the higher the likelihood of adopting its use which is consistent with findings in a study in WWAP (2017), which stated that it is economical to use a resource close to the point of production. 


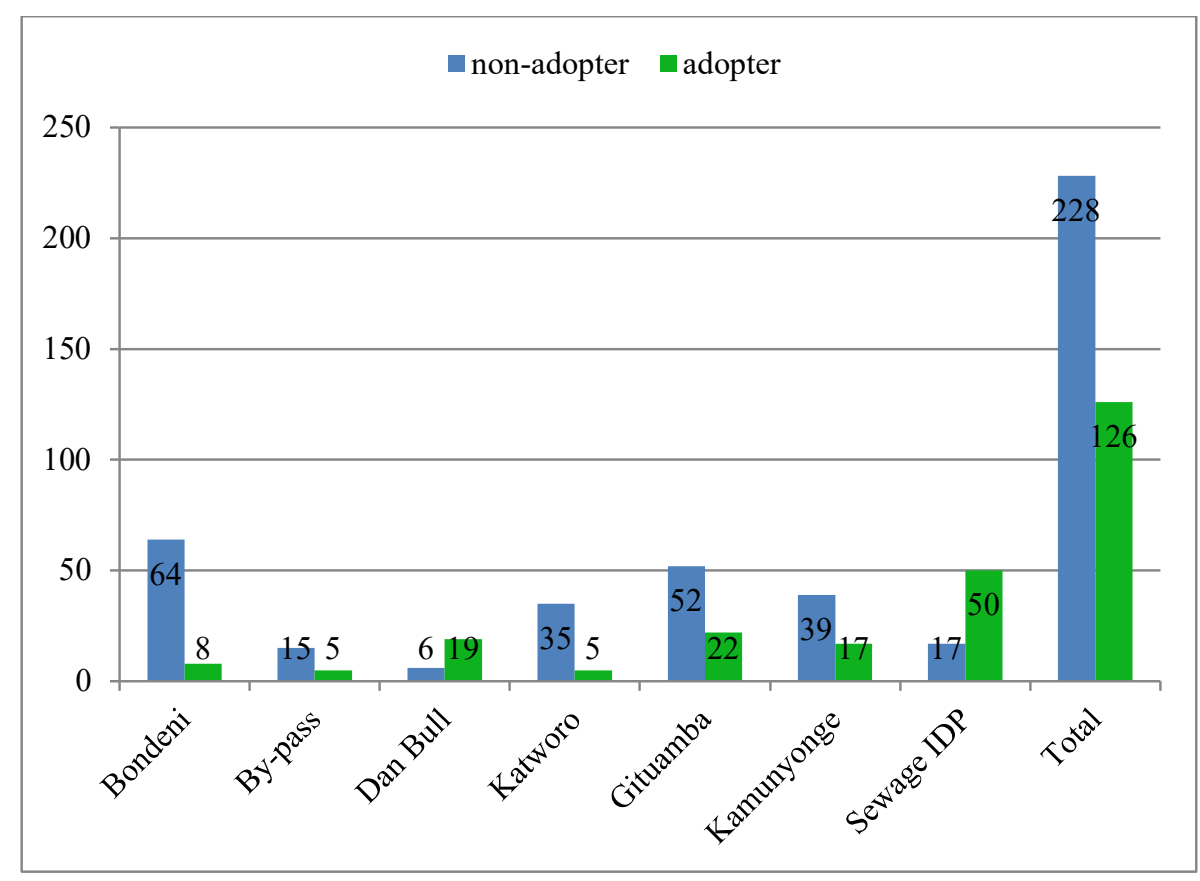

Figure 2: Respondents' Status of Adoption of Wastewater for Livelihood in Ruai.

\subsection{Characteristics of Household Respondents in relation to Adoption of TWW Use}

Table 2 shows the demography of the household respondents in relation to their adoption statuses. Respondents were aged between 18 and 82 years, with a modal age bracket of 31-40 years. There were slightly more males $(55 \%)$ than females $(45 \%)$. More males $(42 \%)$ than females $(28 \%)$ had adopted the use of TWW which could be attributed to the fact that men were having a wider variety of opportunities than women for possible uses of TWW over and above farming, such as building and car wash activities. Most of the adopters were aged between 41 and 50 years old (44\%) followed closely by the age bracket of 51-60 years old. This hypothetically, is the age at which most people are a lot more productive and busy in their already settled occupations. Most of the respondents in the extreme age groups (young and old) were non-adopters, probably because the young ones could still be exploring more options of livelihoods and/or pursuing advanced education while the older folks may have lessened their parental obligations.

In terms of marital status, out of 354 respondents, $(11.0 \%)$ were not yet married, $(76.3 \%)$ were married, $(8.2 \%)$ separated, $(1.1 \%)$ divorced and $8(2.3 \%)$ single mother. More of the separated and divorced respondents were adopters (52\% and 50\% respectively) than non-adopters in the same marital status category. This could be attributed to the fact that they single-handedly fend for their households and have more independence in making decisions. Cumulatively, they could also be having fewer livelihood options than the married counterparts.

The respondents' highest formal education levels decreased from the lowest level - primary school (37.0\%) to the highest level - university (5.4\%). This indicates that there is generally low higher education (tertiary level and above) in the area. As the level of formal education rises, the adoption of TWW use reduces. The level of education is known to influence the level of knowledge, attitude and perception (Njagi, 2013) which might have contributed to low adoption status on the ground.

Most of the respondents were landowners (52.3\%), the rest tenants $(38.4 \%)$ while others, $(7.3 \%)$, were either living in their parents' compounds but fending for themselves or just caretaker of the absentee owners. Their adoption statuses were more or less the same. This indicates that land ownership may not influence the adoption of TWW use in Ruai.

The respondents in Ruai engage in various occupations with majority doing farming as their main occupation (29\%). Farmers again recorded the highest percentage of adopters $(57 \%)$ with the lowest percentage of adopters coming from formal employment $(14 \%)$. This is consistent with findings in other similar studies which reported that more urban households engaged in agricultural activities (Scheierling et al., 2010) and are in most cases unemployed (Kihila, et al., 2014). 
Table 2: Demographic Factors of Household Respondents and Their Adoption Statuses

\begin{tabular}{|c|c|c|c|c|}
\hline \multicolumn{2}{|c|}{ Demographic factor (Variable) } & \multicolumn{2}{|c|}{ Adoption } & \multirow{2}{*}{\begin{tabular}{|c|} 
Tota \\
159 \\
\end{tabular}} \\
\hline Gender & female & $\begin{array}{c}\text { no } \\
115 \\
\end{array}$ & $\begin{array}{c}\text { yes } \\
44 \\
\end{array}$ & \\
\hline & male & 113 & 82 & 195 \\
\hline \multirow[t]{6}{*}{ Marital Status } & not yet married & 30 & 9 & 39 \\
\hline & married & 172 & 98 & 270 \\
\hline & separated & 14 & 15 & 29 \\
\hline & divorced & 2 & 2 & 4 \\
\hline & single mother /never married & 6 & 2 & 8 \\
\hline & No response & & & 4 \\
\hline \multirow[t]{7}{*}{ Age bracket } & $\leq 20$ & 1 & 1 & 2 \\
\hline & $21-30$ & 60 & 21 & 81 \\
\hline & $31-40$ & 66 & 37 & 103 \\
\hline & $41-50$ & 50 & 39 & 89 \\
\hline & $51-60$ & 30 & 19 & 49 \\
\hline & $61-70$ & 19 & 7 & 26 \\
\hline & $71 \leq$ & 2 & 2 & 4 \\
\hline \multirow{5}{*}{$\begin{array}{l}\text { Highest } \\
\text { Education level }\end{array}$} & primary school & 73 & 58 & 131 \\
\hline & secondary / high school & 78 & 49 & 127 \\
\hline & tertiary & 48 & 10 & 58 \\
\hline & university & 17 & 2 & 19 \\
\hline & other & 12 & 7 & 19 \\
\hline \multirow[t]{4}{*}{ Occupancy } & owner & 123 & 62 & 185 \\
\hline & tenant & 84 & 52 & 136 \\
\hline & other & 15 & 11 & 26 \\
\hline & no response & 6 & 1 & 7 \\
\hline \multirow[t]{8}{*}{ Main Occupation } & Formal / salaried employment & 38 & 6 & 44 \\
\hline & farmer & 45 & 59 & 104 \\
\hline & business & 60 & 16 & 76 \\
\hline & transport & 16 & 4 & 20 \\
\hline & casual labour & 35 & 20 & 55 \\
\hline & grocery vendor & 7 & 4 & 11 \\
\hline & construction / masonry / carpenter / mechanic & 25 & 14 & 39 \\
\hline & Any other & 2 & 3 & 5 \\
\hline
\end{tabular}

Note. Values are expressed as number of cases $(n)$.

On the non-demographic characteristics of the respondents, the results in Figure 3 show that most of them agreed that wastewater is a valuable resource for livelihood purposes $(96 \%)$ with a corresponding huge support for TWW use (88\%) and a great willingness to the use wastewater for livelihoods $(81 \%)$. However, this scenario does not necessarily translate to the practical adoption of the use of TWW in the study area, as only $35 \%, 34 \%$ and $35 \%$ respectively adopted in those categories. These findings agree with those in Po et al., (2003) which averred that people can see the logic in using recycled water but remain reluctant to use it.

Likewise most people generally agree to various reasons for the use of wastewater in Ruai such as fresh water scarcity (94\%), TWW being accessible (89\%), reliable (91\%), a source of nutrients $(69 \%) \&$ income $(86 \%)$ and a free resource (89\%), which contrast to the actual adoption represented as follows, $34 \%, 33 \%, 34 \%, 24 \%, 30 \%$ and $31 \%$ respectively.

The results also showed that most (76\%) of the respondents who had ever depended on wastewater directly or indirectly actually adopted its use for their livelihood purposes in Ruai. This indicates that dependency on a resource e.g. wastewater as in having ever used it before, benefitted from its use such as offering labour in and/or procuring produce from farms irrigated with wastewater may contribute to the adoption for its use. While most respondents $(63 \%)$ claimed knowledge of an organization regulating the use of TWW on the ground only $26 \%$ of them had adopted. On the contrary a higher percentage of respondents who claimed 'no knowledge' (73\%) had adopted. This implies that possession of such knowledge could deter adoption of TWW use in Ruai and vice versa among the residents of Ruai. Only a small number (17\%) of the respondents claimed that permission is granted for the use of the TWW by whichever authority. 


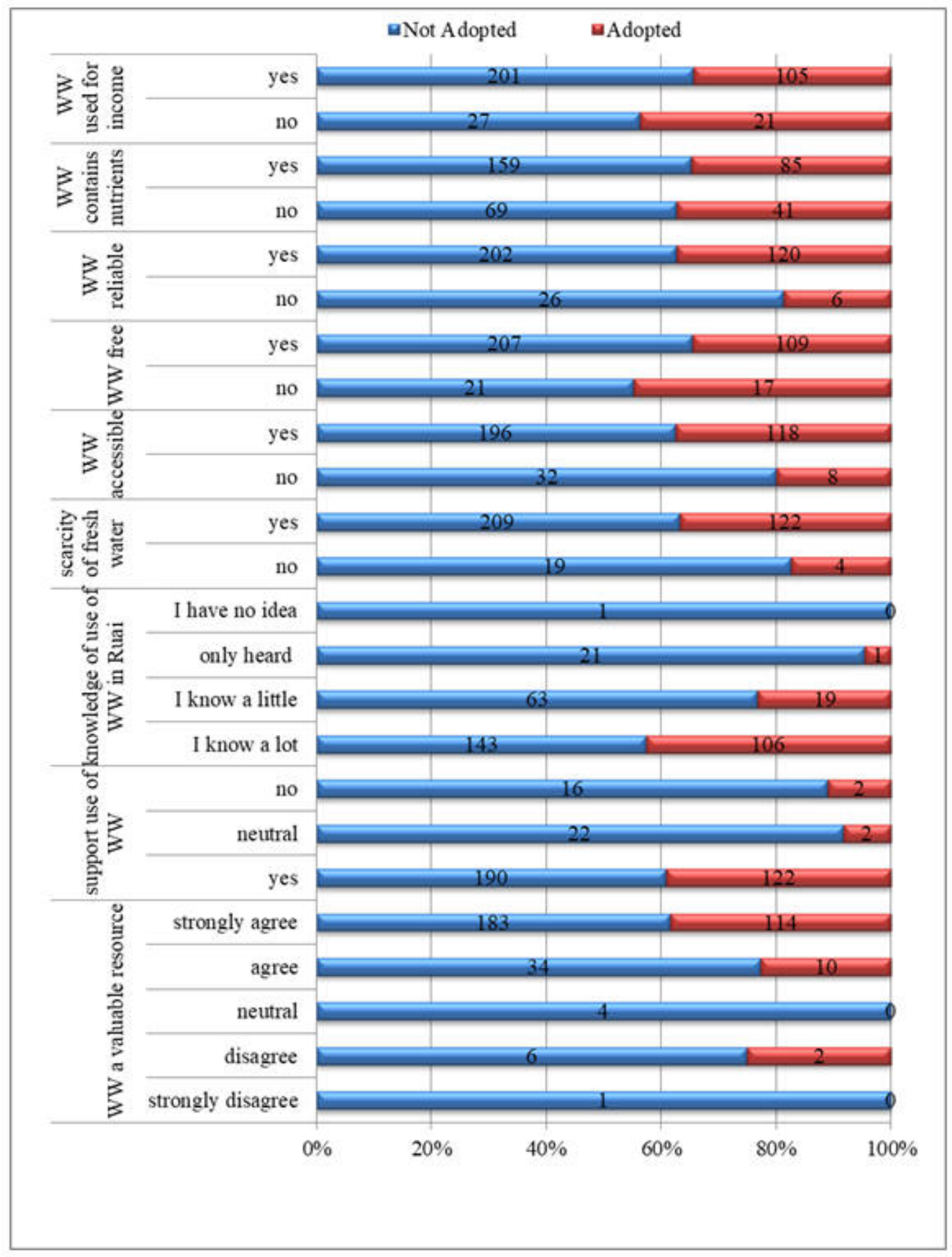

(Continued)

Figure 3: Non-Demographic Factors and Adoption of TWW 


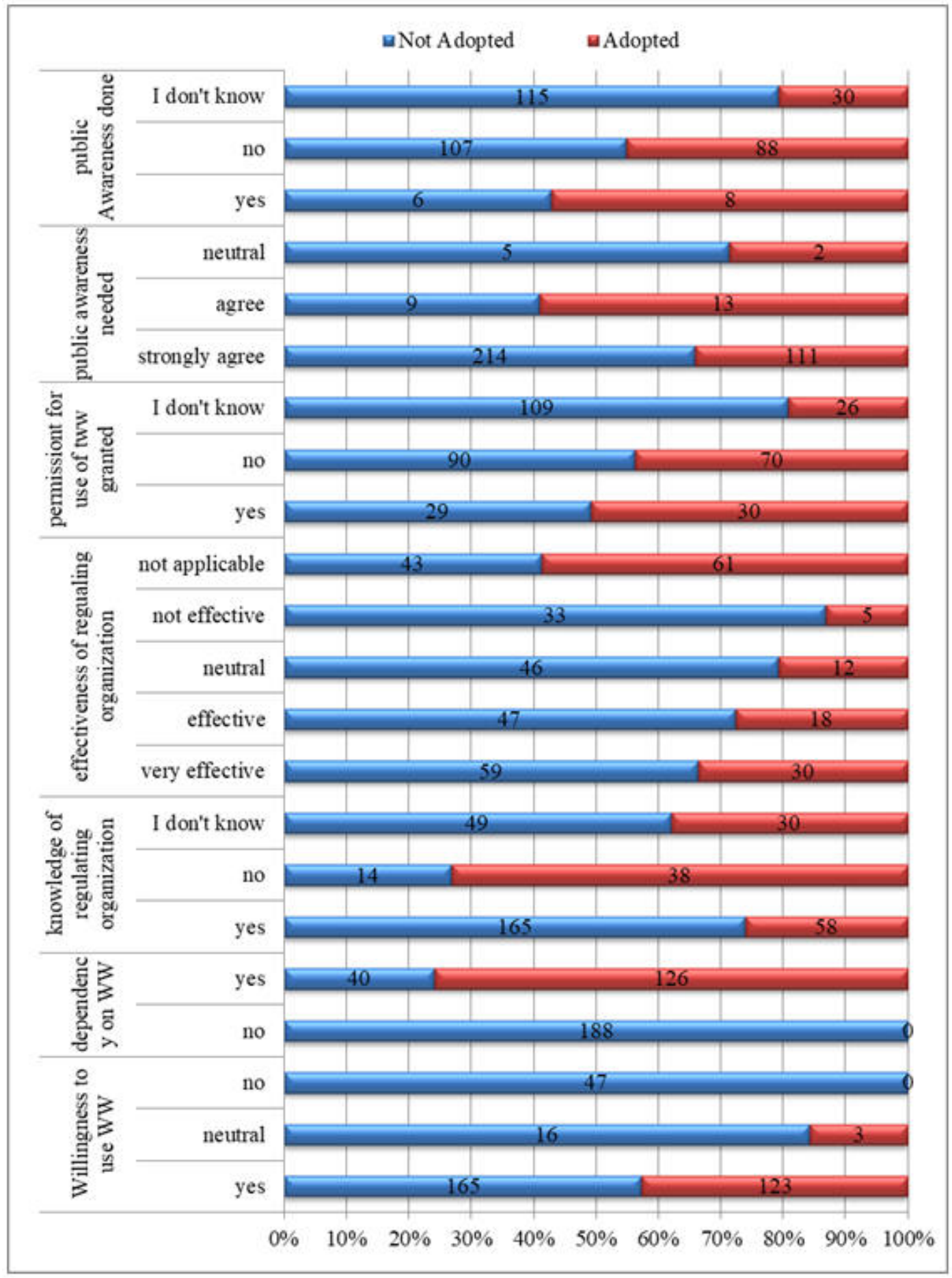

(Continued)

Figure 3: Non-Demographic Factors and Adoption of TWW

\subsection{Empirical Results of Factors Influencing Adoption of TWW use in Ruai}

Logistic regression results for the test of the the null hypothesis which stated that there are no significant factors influencing the adoption of TWW use among communities in Ruai are presented systematically as described in Peng, et al., (2002) and Hyeoun-Ae, (2013) as follows: a) statistical tests of individual predictors; b) an overall evaluation of the logistic model; c) goodness-of-fit statistics; and d) evaluating the predictive accuracy of the model. 
Most of the variables in the study are categorical (nominal or ordinal scaled) in nature. Hence they could not be directly entered into the regression analysis. Instead they needed to be converted into dummy variables and coded accordingly as described in UCLA, (2016b).

3.3.1 Univariate Logistic Regression for Statistical Tests of Individual Predictors

Table 3 shows results of univariate binary logistic regression. Independent variables that significantly influenced adoption of TWW (at $p \leq .05$ ) included; gender, educational level, profession, support, knowledge, dependency inter alia. Marital status, age, length of stay, occupancy, perception, 'it's rich in nutrients', and 'for income' were insignificant $(p>.05)$ in predicting adoption among the respondents. The insignificant variables were excluded in the succeeding multivariate logistic regression analysis as recommended in Burns and Burns, (2008) and Bursac, et al., (2008).

Table 3: Output of Univariate Logistic Regression

\begin{tabular}{llllll}
\hline Predictor & Wald & Sig. & Predictor & Wald & Sig. \\
\hline Gender & 7.8 & .005 & No other source of water & 3.3 & .069 \\
Marital status & 6.5 & .166 & TWW accessible & 4.5 & .033 \\
Age & 1.7 & .187 & TWW free & 1.5 & .215 \\
Education level & 16.6 & .002 & TWW reliable & 4.1 & .043 \\
Occupancy & 2.5 & .476 & TWW has nutrients & 0.2 & .658 \\
Length of stay & .04 & .842 & TWW for income & 1.6 & .206 \\
Profession & 29.4 & .000 & Willingness & 19.2 & .000 \\
Main occupation & 36.7 & .000 & Dependency & 39.2 & .000 \\
Perception* & 4.4 & .359 & Knowledge of organization regulating use of TWW & 34.9 & .000 \\
Support & 11.2 & .004 & Permission for use of TWW & 24.9 & .000 \\
Knowledge & 15.8 & .001 & Awareness & 2.3 & .096 \\
\hline
\end{tabular}

Note: * Wastewater as a valuable resource for livelihood purposes. Significant level at $p \leq .05, T W W=$ Treated wastewater

Multivariate Logistic Regression For Statistical Tests of Predictors

Following the selection of the significant variables in the univariate logistic regression, Appendix A shows their categorical codings as was used in the study to run the multivariate regression. It is reasonable to consider one of the categories of a given variable as a reference category to which each other category should be compared as described in Wuensch (2014).

The output of logistic regression comes in form of many tables. The study presented the most important ones as pointed out in Burns and Burns (2008). Table 4 shows the classification of the observed and predicted adoption of the TWW use for livelihoods purposes in Ruai by the model without predictors (null model). An overall percentage accuracy of $64.4 \%$ is given. This indicates that if we knew nothing about our predictor variables, we would be correct $64.4 \%$ of the time in predicting that for every case, the subject will adopt the use TWW for their livelihoods in Ruai.

Table 4: Classification by the Null Model

\begin{tabular}{llllll}
\hline & & \multicolumn{2}{c}{ Predicted } & Percentage \\
\cline { 3 - 5 } & & & \multicolumn{2}{c}{ Adoption of wastewater } & correct \\
\cline { 3 - 5 } & Observed & & 0 & 0 & 100.0 \\
Step 0 & Adoption of wastewater & 0 & 228 & 0 & 0.0 \\
& & 1 & 126 & 0.4 & 64.4 \\
\hline
\end{tabular}

As results in Table 5.0 show, the SPSS output of logistic regression for the null model gave a Wald chisquare; $\chi^{2}=28.54$, df (1), $p<0.05$, indicating that the model was statistically significant. So we rejected the null hypothesis that the coefficients of interests are not simultaneously equal to zero $(\beta \neq 0)$. This means that including statistically significant predictors should not only lead to better prediction resulting in a statistically significant improvement in the fit of the model as described in statistical consulting group [UCLA], (2016a) but should also increase the percentage of correct classification significantly if the model is good (Wuensch, 2014). The model's odds ratio $[\operatorname{Exp}(B)]=.553$ means that the predicted odds of obtaining a case having adopted wastewater use for livelihood purposes in Ruai are 0.553 . This gives a probability of adopting wastewater among households of Ruai of 0.356 or $35.6 \%$.

A test of the model with predictors (full model) versus a model with intercept only was statistically significant, $\chi^{2}(11, \mathrm{~N}=354)=306.06, p \leq .05$ (Appendix B, Table B1) as described in Burns and Burns, (2008) and Wuensch, (2014), indicating that the predictors as a set in the final model reliably distinguished between adopters and nonadopters of TWW use in Ruai. The significance of the test also shows that the given model with $k$ independent variables provided a better fit to the data by demonstrating an improvement over the model with no independent variables (the null model) as described in (Hyeoun-Ae, 2013). The model was able to correctly classify (predict) 
$91.0 \%$ of the cases (Table 7 ), an improvement from $64.4 \%$ for the null model.

Table 5 further shows the predictors to the final model and their corresponding logistic regression coefficient $(\beta)$, Wald $\chi^{2}$ test and odd ratio $[\operatorname{Exp}(\beta)]$. The variables that are statistically significant towards the adoption of wastewater use among the households of Ruai community are; gender (Wald $\chi^{2}(1)=5.31, p<.05$ ), the overall variable 'main occupation' (Wald $\chi^{2}(7)=21.06, p<.05$ ), dummy variable farming (M.O.1) [Wald $\chi^{2}(1)=5.31$, $p<.05$ ], dependency on wastewater (Wald $\chi^{2}(1)=40.59, p<.05$ ), knowledge of the organization regulating use of TWW in Ruai (Wald $\chi^{2}(2)=6.76, p<.05$ ), dummy variable 'no knowledge of the organization regulating use of TWW in Ruai' (Wald $\chi^{2}(1)=4.24, p<.05$ ), and dummy variable 'I don't know any organization regulating use of TWW in Ruai' (Wald $\chi^{2}(1)=4.16, p<.05$ ). Therefore, we have enough evidence not to accept the hypothesis that the aforementioned variables do not have effect $(\beta \neq 0)$ on the probability of adopting use of TWW in Ruai. There are no coefficients listed for the variables overall 'main occupation', 'knowledge of regulating organization' and 'public awareness done' because they are not variables in the model. Rather their respective dummy variables which are in the equation have coefficients. The dummy variable 'farming' (M.O.1) is statistically significantly different $(p=.007)$ from the reference variable 'formal employment'. The other dummy variables; 'business', 'transport', 'casual labour', 'vocational' and 'other occupations' are not statistically significantly different from the reference variable formal employment with a $p \geq .05$.

Table 5: Estimates of the Null and Final Logistic Regression Model

\begin{tabular}{|c|c|c|c|c|c|c|c|}
\hline & Predictor Variable & $B$ & S.E. & Wald & df & Sig. & $\operatorname{Exp} B$ \\
\hline \multirow{15}{*}{$\begin{array}{l}\text { Step } 0 \\
\text { Step } 8\end{array}$} & None (constant) & .593 & .111 & 28.543 & 1 & .000 & .553 \\
\hline & gender(1) & -1.103 & .479 & 5.31 & 1 & .021 & .33 \\
\hline & Main occupation (M.O) & & & 21.06 & 7 & .004 & \\
\hline & Farming (M.O 1) & 2.013 & .874 & 5.31 & 1 & .021 & 7.5 \\
\hline & Business (M.O 2) & .719 & .896 & .64 & 1 & .423 & 2.05 \\
\hline & Transport (M.O 3) & -1.003 & 1.021 & .96 & 1 & .326 & .37 \\
\hline & Casual labour (M.O 4) & -.162 & .826 & .04 & 1 & .845 & .85 \\
\hline & Grocery (M.O 5) & -.132 & 1.070 & .02 & 1 & .902 & .88 \\
\hline & Vocational (M.O 6) & 1.667 & 1.174 & 2.02 & 1 & .155 & 5.30 \\
\hline & Others (M.O 7) & 3.268 & 3.250 & 1.01 & 1 & .315 & 26.26 \\
\hline & Dependency (1) & 6.921 & 1.086 & 40.59 & 1 & .000 & 1013.0 \\
\hline & Regulating organization & & & 6.76 & 2 & .034 & \\
\hline & Regulating organization (no) & 1.329 & .646 & 4.24 & 1 & .039 & 3.78 \\
\hline & $\begin{array}{l}\text { Regulating organization (I don't } \\
\text { know) }\end{array}$ & 1.053 & .516 & 4.16 & 1 & .041 & 2.87 \\
\hline & Constant & -6.457 & 1.324 & 23.77 & 1 & .000 & .002 \\
\hline
\end{tabular}

Note. Step 0, also called constant means ' no variable in the model', Step 8 =Final step in the backward regression process, Variable(s) entered on step 1: gender, education level, profession, main occupation, support, knowledge, reliable, willingness, dependency, regulating organization, and permission. $B=$ Odds; $\mathrm{df}=\mathrm{degrees}$ of freedom; $\mathrm{SE}=$ Standard error; $\operatorname{Exp} B=$ Odds ratio $[\mathrm{OR}], P \leq .05$

The variable 'dependency on wastewater' was the most significant predictor (Wald $\chi^{2}(1)=40.59, p<.05$, $\mathrm{OR}=1013.0$ ). This means that those who have ever depended on TWW for their livelihoods were 1013.0 times more likely to adopt the use of TWW than those who had not. The odds are a lot lower for women $(0.33$ times for men). Inverting the odds ratio for gender, for ease of interpretation, indicates that when holding all other variables constant, a man is 3.0 (that is, 1/.33) times more likely to adopt the use of wastewater for livelihoods than a woman in Ruai. This agrees with previous studies showing that acceptability of water reuse is higher for men than women (Aitken, et al., 2014).

The overall variable 'main occupation' is statistically significant. Respondents having farming as their main occupation had an odds ratio of 7.5 in reference to those in formal employment. This means that the odds of adopting TWW use by respondents whose main occupation is farming are 7.5 times those of respondents whose main occupation is salaried or formal employment. This is consistent with a report by Scheierling et al., (2010) indicating that one of the powerful drivers for the expansion of wastewater irrigation is that more urban households engaged in agricultural activities.

Knowledge or lack of it of any institution/ organization (public or private) that regulate or control the use of wastewater in Ruai was a significant predictor of the adoption of TWW use. These findings agree with those in (Bdour, et al., 2009) which reported that the involvement of municipalities and nongovernmental organizations encourage and support any effort being invested to increase the familiarity of the public in issue of proper management and utilization of wastewater

Predictors which were not significant $(p \leq .05)$ towards adoption of wastewater use though they contributed significantly to the fitting of the final model included dummy variables of the main occupation (business, transport, 
casual, grocery vending and construction). This means that we do not have enough evidence for rejecting the hypothesis stating that these variables have no effect on the probability of adopting use of TWW.

The overall regression equation for predicting the probability of adoption of wastewater use in Ruai communities $(P)$ was:

Logit $(y)=-6.46-1.10 *$ gender $+2.01 * M . O(1)+.72 * M . O(2)-1.00 * M . O(3)-.16 *$ M.O (4) - .13* M.O (5)

$+1.67 *$ M.O (6) $+3.27 *$ M.O (7) $+6.92 *$ dependency $(1)+1.33 *$ regorganzn (1) $+1.05 *$ regorganzn (2)

Where: Gender is male (reference category) \& female; MO (Main Occupation) with Formal employment (reference), MO (1) = farming, 2= business, 3= transport, 4=casual, 5=grocery, $6=$ construction, 7=others; dependency, Yes, 1=No (reference); regorganzn (knowledge of regulating organization): Yes (reference), $1=$ No, $2=$ I don't know.

All the selected variables were entered in the first step. Those with comparatively low score values and a nonsignificant value (at $p>0.05$ ) were removed one by one in each step, based on the $p 1$-value often set to .05, while removal of a previously entered variable is based on the $p 2$-value set to 0.1 as described in Kandler, et al, (2015) Mauša, et al, (2012). In this regard the variables that did not significantly contribute $(p>0.05)$ to the final predictors' model for the adoption of wastewater use for livelihood purposes in Ruai resulting to their removal from the final model included; knowledge of use of TWW in Ruai, education level, reliability of wastewater, permission to use the wastewater, level of education, reliability of TWW, profession of the respondent, willingness to use TWW and support for the use of TWW in Ruai, see Appendix B, Table B3). The findings on reliability and nutrient value of TWW contrasts studies conducted by Jiménez et al., 2010, Khalil et al., 2011 that reported wastewater as being used due to its reliability and high nutrient value.

3.3.2 Overall Model Evaluation

As results in Table 6 show, the likelihood ratio test statistic $[(\chi 2(11)=154.87, p<.05)]$ for the overall assessment of the logistic model shows that the final model was more effective than the null model (Hyeoun-Ae, 2013). So the study failed to accept $H_{0}(\beta=0)$ with the conclusion that there is evidence that at least one of the independent variables contributed to the prediction of the final outcome (adoption of TWW use). A computed likelihood ratio test $[(\chi 2(22)=20.436, p=.556)]$ for the difference in $-2 \log$ likelihood of the models with all predictors (step1) and the final model (final step), shows no difference in their fit. This indicates no significant loss in performance of the final model after backward regression process which corroborated with the overall score test of the final model $[(\chi 2(22)=18.562, p=.672)]$.

The inferential goodness-of-fit test, the Hosmer-Lemeshow test $(\chi 2=5.02)$ was insignificant $(p>.05)$, indicating that the model prediction does not significantly differ from the observed and the model was fit to the data (Hyeoun-Ae, 2013; Peng et al., 2002). This shows a strong relationship between all of the independent variables (predictors), taken together and dependent variable (adoption of TWW use). The result of the Omnibus tests of model coefficients, for the-final model $\left(\chi^{2}(11)=306.06, P<.05\right)$ indicates that the final full model with the remaining predictors had a good fit towards the data and fitted significantly better than the model with no predictor (Wuensch, 2014; Hyeoun-Ae, 2013). The final model explained between 57.9\% (Cox and Snell R Square ) and $79.5 \%$ (Nagelkerke $R^{2}$ ) of the variance in the adoption of wastewater use (Appendix B, Table B2). This also confirms the model's good fit of our data.

Table 6: Overall Model Evaluation and Goodness-of-fit Statistics

\begin{tabular}{llccc}
\hline Test & Category & $\chi^{2}$ & df & $p$ \\
\hline Overall Model evaluation & Likelihood ratio test & 154.87 & 11 & .000 \\
& Score test & 18.562 & 22 & .672 \\
\multirow{2}{*}{ Goodness-of-fit test } & Hosmer \& Lemeshow & 5.02 & 8 & .756 \\
& Omnibus test & 306.06 & 11 & .000 \\
\hline
\end{tabular}

Note: Cox and Snell $\mathrm{R}^{2}=.579$, Nagelkerke $\mathrm{R}^{2}=.795$

Results on the predictive accuracy of the final model are shown in Table 7. As described in Wuensch, (2014) and Peng,et al., (2002) the results show that $96.8 \%$ of the occurrence of adoption was correctly predicted (sensitivity), $87.7 \%$ of the non-occurrence of adoption was correctly predicted (specificity). Overall our predictions were correct 322 out of 354 times, for an overall success rate of $91 \%$ up from $64.4 \%$ for the model with intercept only. This shows a great improvement by the final model.

A false positive prediction (18.6\%) that adoption would occur when, in fact, it did not, as well as a false negative prediction $(2.0 \%)$ that adoption would not occur when, in fact, it did occur were observed (Wuensch, 2014). 
Table 7: Classification by the Final Model

\begin{tabular}{llcccc}
\hline & Observed & \multicolumn{3}{c}{ Predicted } \\
\cline { 3 - 5 } & & \multicolumn{3}{c}{ Adoption } & Percentage correct \\
\cline { 3 - 5 } & & no & 200 & yes & 87.7 \\
\multirow{3}{*}{ Step 15 } & Adoption & yes & 4 & 122 & 96.8 \\
& Overall Percentage correct & & & 91.0 \\
\hline
\end{tabular}

Note. Sensitivity $=122 / 126=96.8 \%$, Specificity $=200 / 228=87.7 \%$, Positive predictive $=28 / 150=18.6 \%$, Negative predictive $=4 / 204=2.0 \%$.

\subsection{Conclusion and Recommendations}

A slightly more than one-third (35.6\%) of households respondents in Ruai have adopted the use of TWW for their livelihoods. The study's null hypothesis was rejected as there was sufficient evidence showing that several factors had statistically significant influence on the adoption of TWW use among the communities in Ruai. From the univariate logistical analyses, the demographic factors significantly influencing the adoption of TWW were respondent's gender, education level, main occupation and profession while the non-demographic ones included, accessibility and reliability of TWW, willingness to use TWW and dependency on TWW. Overall, from the multivariate analyse, the factors that significantly influenced the adoption of TWW in Ruai were demographic; gender where more males than female adopted its use, individual's main occupation with those engaging in farming opting for the adoption more than those in any other occupation, and non-demographics; dependency on wastewater directly or indirectly, and having the knowledge of organization that regulate the use of the resource in the area.

Based on the findings of the study, there is need for enhancing the significant factors related to the adoption of TWW use and at the same time addressing the insignificant ones as identified in the present study by the stakeholders when undertaking projects or programmes aimed at enhancing sustainable community livelihoods in Ruai through the adoption of TWW use.

There is a need to confront the realities of wastewater use in Ruai by creating awareness which incorporates the study's influencing factors of adoption among communities in Ruai in order to find sustainable solutions. In particular, raising awareness on the adoption of TWW use should target women, those in formal employment and in non-farming livelihood activities. According to Keremane and Mckay, (2006), by providing knowledge and information on the 'current best practices' and communicating this information in a form that is understandable to the key stakeholder groups such as the local community, any reuse scheme can be instrumental in achieving sustainability with its economic, social, and environmental dimensions as evidenced in the case of the Virginia Pipeline Scheme in Australia.

The demographic and non-demographic variables of the present study should be considered by both the Kenya's national and the Nairobi county government policy makers when undertaking policy review and development on matters of integrated management of wastewater aimed at enhancing community livelihoods. This is conceptualized from sustainable livelihood framework whose one of the key strengths is its potential for 'linking the macro to the micro', that is establishing connection between local realities and the level at which policies intended to change these realities are formulated (Shankland, 2000). According to Bahri, (2009) and Oyebode, (2015) wastewater is a water resource management and water quality issue and its reuse is an important option for integrated water resources management. Water reclamation and recycling are considered as key components of water and wastewater management policies around the world (Keremane and Mckay, 2006).

The study further recommends a further research study on, (1) the contributions of awareness and level of education among the communities of Ruai to the adoption of TWW use for livelihood purposes, (2) the roles, effectiveness and impact of actors within governmental, non-governmental and private-sector organizations in controlling and regulating wastewater use in Ruai and Kenya at large.

\section{Acknowledgments}

First and foremost, I would like to thank the Almighty God for giving me the capacity that I needed to walk through this academic journey from the inception to the very end. I did enjoy from him sufficient grace, favour, renewed strength, good health, financial breakthrough inter alia in every step of the way. I also want to acknowledge several people who supported me in this noble task. First is to thank my supervisors, Dr A. Wamukota and Dr M. Mwakumanya for their guidance and scholarly advice. I am also grateful to my research assistant Ms W. Changwony for her exemplary assistance in carrying out the fieldwork in Ruai. I also want to thank Nairobi water and sewerage company (NWSC) and its affiliate Dandora estate sewage treatment works (DESTW) for giving me access to their treatment facilities and the participating household respondents for giving me their time and data sought for. I cannot forget Mrs Ceciliah Karanu for assisting me in data entry. Lots of appreciation and thanks also 
goes to my immediate family led by my wife, Emmah, for their consistent and selfless support, company and prayers in this regard. Finally every other person who played a role in one way or another for the success of this study is also highly appreciated.

Acknowledgments: First and foremost, I would like to thank the Almighty God for giving me the capacity to walk through this academic journey, which forms part of the requirements for the Doctor of Philosophy degree of Pwani University, from its inception to the very end. I did enjoy from him sufficient grace, favour, renewed strength, good health, financial breakthrough inter alia in every step of the way. I also want to acknowledge several people who supported me in this noble task. First is to thank my supervisors, Dr A. Wamukota and Dr M. Mwakumanya for their guidance and scholarly advice. I am also grateful to my research assistant Ms W. Changwony for her exemplary assistance in carrying out the fieldwork in Ruai. I also want to thank Nairobi city water and sewerage company (NCWSC) and its affiliate Dandora estate sewage treatment works (DESTW) for giving me access to their treatment facilities and the participating household respondents for giving me their time and data sought for. I cannot forget Mrs Ceciliah Karanu for assisting me in data entry. Lots of appreciation and thanks also goes to my immediate family led by my wife, Emmah, for their consistent and selfless support, company and prayers in this regard. Finally every other person who played a role in one way or another for the success of this study is also highly appreciated.

\section{References}

Angatia, P.A. (2013). Factors influencing wastewater management and re-use in peri-urban areas in Kenya: A case of Ongata Rongai. [Master Thesis], Nairobi: University of Nairobi.

Aitken, V., Bell, S., Hills, S. and Rees, L. (2014). Public acceptability of indirect potable water reuse in the South-East of England [Online]. Available at: http://discovery.ucl.ac.uk/ (Accessed: 7 September 2017)

Almas, A. A. M., and Scholz, M. (2006). Potential for wastewater reuse in irrigation: Case study from Aden (Yemen). International Journal of Environmental Studies, 63(2):131-412. doi: 10.1080/00207230500505569

Amare, E., Kebede, F., Kloos, H., and Mulat, W. (2017). Wastewater confronting realities for sustainable livelihood in developing countries: Case Study Mekelle University, Ethiopia. Water Conservation Science and Engineering, 2: 21-30. doi: 10.1007/s41101-017-0021-7

Asano, T and Bahri, A. (2011). Global challenges to wastewater reclamation and reuse. [Online]. Available at: https://www.researchgate.net/publication/ (Accessed: 20 September 2019)

Bahri, A. (2009). Managing the other side of the water cycle: Making wastewater an asset. Technical Committee. Papers No. 13. Global Water Partnership. Sweden.

Buechler, S. (2004). A sustainable livelihoods approach for action research on wastewater use in agriculture In: Scott C, A., Faruqui, N.I., and Raschid-Sally L (Eds), Wastewater use in irrigated agriculture: confronting the livelihood and environmental realities. (pp. 25-40). IWMI/IDRC-CRDI/CABI, Wallingford, UK

Bdour, A.N., Hamdib, M.R. \& Tarawneh, Z. (2009). Perspectives on sustainable wastewater treatment technologies and reuse options in the urban areas of the Mediterranean region. Desalination 237 (2009):162-174. doi:10.1016/j.desal.2007.12.030.

Buechler, S., Mekala, G.. D. and Keraita, B. (2006).Wastewater use for urban and peri-urban agriculture. RUAF Foundation: Resource Centres on Urban Agriculture and Food Security. Netherlands, IDRC, Canada and IIRR publishers, the Philippines.

Burns, R. P. and Burns, R. (2008). Business research methods and statistics using SPSS. SAGE Publications Ltd, UK. [Online]. Available at: https://www.staff.ncl.ac.uk/mike.cox/III/spss10.pdf. (Accessed: 1 February 2018)

Bursac, Z., Gauss, C. H., Williams, D.K., and Hosmer, D.W. (2008). Purposeful selection of variables in logistic regression. Source Code for Biology and Medicine, 3:17 doi: 10.1186/1751-0473-3-17

Carr, G. and Potter, R. B. (2013). Towards effective water reuse: drivers, challenges and strategies shaping the organizational management of reclaimed water in Jordan. The Geographical Journal, 179 (1): 61-73. doi: 10.1111/j.14754959.2012.00478.x

Corcoran, E., Nellemann, C., Baker, E., Bos, R., Osborn, D., and Savelli, H. (eds). 2010. Sick Water? The central role of wastewater management in sustainable development. A Rapid Response Assessment. United Nations Environment Programme, UN-HABITAT, GRID-Arendal. www.grida.no ISBN: 978-82-7701-075-5. Birkeland Trykkeri AS, Norway

[GEF CReW] GEF Caribbean Regional Fund for Wastewater Management Project (2015). Regional wastewater management policy template and tool kit. CEP Technical Report: 88 . UNEP.

Hyeoun-Ae Park, (2013). An introduction to logistic regression: From basic concepts to interpretation with particular attention to nursing domain. J Korean Acad Nurs. 43(2): 154-164. doi: 10.4040/jkan.2013.43.2.154

IBM Corporation (2011). Stepwise Variable Selection: Logistic Regression Algorithms. IBM SPSS Statistic Version 20. IBM Corporation.

[IWA] International Water Association, (2018). The reuse opportunity. wastewater Report 2018. [Place unknown], IWA. [Online]. Available at: https://www.iwa-network.org/ (Accessed: 10 February 2020)

Jamil, S.A.M., Abdullah, M.A.A., Long, K.S., Jupri, N.F.M.,and Mamat, M. (2018). A stepwise logistic regression analysis: an application toward poultry farm data in Johor. International Journal of Engineering \& Technology. 7 (3.28): 68-71

Jiménez, B. (2006) Irrigation in developing countries using wastewater. International Review for Environmental Strategies, 6(2): $229-50$ 
Jiménez, B., Drechsel, P., Koné, D., Bahri, A., Raschid-Sally, L., and Qadir, M. (2010). Wastewater, sludge and excreta use in developing countries: an overview. In: Drechsel,P., Scott,C.A., Raschid-Sally,L., Redwood,M. and Bahri,A.[eds] Wastewater Irrigation and Health: Assessing and Mitigating Risk in Low-Income Countries. Earthscan, London, pp. 328

Kabul. (2011). Water Scarcity, Livelihood and Conflict [Online]. Available at: http://www.cpau.org.af/ (Accessed: 1 July 2014)

Kaluli, J. W., Githuku, C., Home P. and Mwangi, B.M. (2011). Towards a national policy on wastewater reuse in Kenya. Policy on wastewater. JAGST Vol. 13(1) 116-125

Kandler, K., Jensen, M. E., Nilsson, J.C, Møller, C. H, and Steinbrüchel, D. A. (2015). Arterial pressure during cardiopulmonary bypass is not associated with acute kidney injury. Acta Anaesthesiologica Scandinavica. 59 (2015): 625631 doi: 10.1111/aas. 12484

Kellis, M., Kalavrouziotis, I.K. and Gikas, P. (2013). Review of wastewater reuse in the mediterranean countries, focusing on regulations and policies for municipal and industrial applications. Global NEST Journal, 15(3): 333-350.

[KNBS] Kenya National Bureau of Statistics. (2009). The 2009 Population and Housing Census. Government Printers, Nairobi. Kenya.

Keremane, G. B. and Mckay, J. (2006). Successful wastewater reuse scheme and sustainable development: a case study in Adelaide, Wastewater Reuse and Sustainable Development. doi:10.1111/j.1747-6593.2006.00062.x.

Khalil, S. and Kakar, M.K., (2011) Agricultural use of untreated urban wastewater in Pakistan. Asian Journal of Agriculture and Rural Development, 1(1): 21-26. AESS Publications

Kihila, J., Mtei, K.M., and Njau, K.N. (2014). Wastewater treatment for reuse in urban agriculture; the case of Moshi Municipality, Tanzania. Physics and Chemistry of the Earth, (72-75): 104-110. Elsevier Ltd.

Kothari, C.R. (2004). Research methodology: methods and techniques (2nd revised edn).New age International (P) Limited, Publishers. India.

Kumar, R. (2011). Research methodology, a step-by-step guide for beginners, (3 ${ }^{\text {rd }}$ edn). SAGE publication Ltd, London.

Kumar, S. (2014). Study on wastewater recycling and reuse. International Journal of Applied Engineering Research. 9(3): 329334

Lyu, S., Chen, W., Zhang, W., Fan, Y. and Jiao, W. (2016). Wastewater reclamation and reuse in China: opportunities and challenges. Journal of Environmental Sciences, 39 (2016): 86 - 9 6. doi: 10.1016/j.jes.2015.11.012

Mahjoub, O., Mekada, M. and Gharbi, N. (2016). Good irrigation practices in the wastewater irrigated area of Ouardanine, Tunisia. In: Hettiarachchi, H. and Reza Ardakanian, R. (eds). Safe Use of Wastewater in Agriculture: Good Practice Examples. UNU-FLORES

Mara, D. (2001). Appropriate wastewater collection, treatment and reuse in developing countries. Proceedings of the Institution of Civil Engineers Municipal Engineer 145 Issue 4. pp. 299-303.

Mauša, G., Grbac, T. G. and Bašić, B. D. (2012). Multivariate logistic regression prediction of fault-proneness in software modules. Conference Paper: MIPRO, 2012 Proceedings of the 35th International Convention MIPRO Project: https:/www.researchgate.net/project/Analiza-i-inovativni-pristupi

Mburu, S.W. (2016). Relationship between socio-economic exclusion and community based waste management practices in Kibera informal settlements, Nairobi county, Kenya. (Doctoral Thesis), Kenyatta University. Nairobi

McDonald, J.H. (2014). Handbook of biological statistics (3rd edn). Sparky House Publishing, Baltimore, Maryland.

Mekala, G. D., Davidson, B., Samad, M. and Boland, A. M. (2008). Wastewater reuse and recycling systems: a perspective into India and Australia. Working Paper 128. Colombo, Sri Lanka: International Water Management Institute. 35p.

Mireri, C., Latema, S. and Majale, C. (2007).Water and sanitation delivery in kenya. In: Waswa, F. (Ed), Environment and sustainable development: A guide for higher education in Kenya Vol.II, pp.275-281, Kenyatta University, Nairobi.

Mugenda, O.M. and Mugenda, A. G. (2003). Research methods: quantitative and qualitative approaches. Acts press, Nairobi, Kenya.

[NCWSC] Nairobi City Water and Sewerage Company (2015). Waste water treatment process. [Online] Available at: http://www.nairobiwater.co.ke/index.html/ (Accessed: 31 March 2015)

Njagi, J. M. (2013). Assessment of heavy metal concentration in the environment and perceived health risks by the community around Kadhodeki dumpsite, Nairobi County. (Doctoral Thesis), Kenyatta University, Nairobi

Norušis, M. J. (2008). SPSS 16.0 Guide to data analysis. Upper Saddle River, N.J. 07458: Prentice Hall, Inc.

Omran, A. (2011). Factors influencing water treatment management performance in Malaysia: a case study in Pulau Pinang. Annals of Faculty Engineering Hunedoara - International Journal of Engineering. Tome Ix. Fascicule 1. ISSN $1584-$ 2665

Opaa, B. and Omondi, G. (2012). Wastewater production, treatment, and use in Kenya. Third Regional Workshop 'Safe Use of Wastewater in Agriculture', 26-28 September 2012, Johannesburg, South Africa.

Oyebode, O.J. (2015). Effective management of wastewater for environment, health and wealth in Nigeria. International Journal of Scientific \& Engineering Research, 6 (7): 1028-1059.

Peng, C.Y.J., Lee, K.L., and Ingersoll, G.M. (2002). An introduction to logistic regression analysis and reporting. Journal of Educational Research 96(1): 3-14

Po M., Kaercher, J.D. and Nancarrow, B. E. (2003). Literature review of factors influencing public perceptions of water reuse. Technical Report 54/03. CSIRO Land and Water. Melbourne

Pourhoseingholi, M. A., Baghestani, A. R., and Vahedi, M. (2012). How to control confounding effects by statistical analysis. Gastroenterol Hepatol Bed Bench 5(2):79-83

Qadir, M., Wichelns, D., Raschid-Sally, L., McCornick, P.G., Drechsel, P., Bahri, A. and Minhas, P.S. (2010). The challenges of wastewater irrigation in developing countries. doi: 10.1016/j.agwat.2008.11.004

Salkind, N.J. (Ed). (2007). Encyclopedia of measurement and statistics, Vol. 2. ISBN 1-4129-1611-9 or 978-1-4129-1611-0. SAGE. 
Scheierling, S.M., Barton, C., Mara, D.D., and Drechsel, P. (2010). Improving wastewater use in agriculture; an emerging priority. (Policy Research working paper; no. WPS 5412). Washington, DC: World Bank. [Online]. Available at: http://documents.worldbank.org/curated/en/710411468176653818/. [Accessed: 1September 2016)

Shankland, A (2000). Analysing policy for sustainable livelihoods. IDS Research Report 49. Institute of Development Studies, Brighton, England.

Shomar, B. and Dare A. (2015). Ten key research issues for integrated and sustainable wastewater reuse in the Middle East. Environmental Science and Pollution Research, 22: 5699-5710 doi: 10.1007/s11356-014-3875-7

Sigoria, E. N. (2012). Heavy metal pollution in Red Haricot beans (Phaseolus Vulgaris) and cowpeas (Vigna Unguiculata) grown using untreated sewage water in Ruai, Nairobi, Kenya. [Master's Thesis]. Kenyatta University, Nairobi

Taherdoost, H. (2017). Determining sample size; how to calculate survey sample size. International Journal of Economics and Management Systems, 2(2017): 237-239. Available at: http://www.iaras.org/iaras/journals/ijems

[UCLA]: Statistical consulting group (2016a). How are the likelihood ratio, Wald, and Lagrange multiplier (score) tests different and/or similar? [Online] Available at: https://stats.idre.ucla.edu/other/mult-pkg/faq/general/faqhow-are-thelikelihood-ratio-wald-and-lagrange-multiplier-score-tests-different-andor-similar/ (Accessed: 4 December 2019)

[UCLA] Statistical consulting group (2016b). Introduction to regression with SPSS lesson 3: SPSS regression with categorical predictors. [online] Available at: https://stats.idre.ucla.edu/spss/seminars/introduction-to-regression-with-spss/introreglesson3/ (Accessed: 22 August 2019)

Vedachalam, S. and Mancl, K.M. (2010). Water resources and wastewater reuse: perceptions of students at the Ohio State University Campus. Ohio Journal of Science: 110(5): 104-113.

Vigneswaran, S. and Sundaravadivel, M. (2004). Recycle and reuse of domestic wastewater, In. Wastewater recycle, reuse, and reclamation, [Ed. Saravanamuthu (Vigi) Vigneswaran], in Encyclopedia of Life Support Systems (EOLSS), Developed under the Auspices of the UNESCO, Eolss Publishers, Oxford, UK

Weldesilassie, A. B., Frör,O., Boelee,E. and Dabbert, S. (2009). The economic value of improved wastewater irrigation: a contingent valuation study in Addis Ababa, Ethiopia. Journal of Agricultural and Resource Economics 34(3): 428-449

Wemali, E.N.C. (2014). Contribution of cultivated african indigenous vegetables to agro-biodiversity conservation and community livelihood in Mumias sugar Belt, Kenya. [Doctoral thesis]. Kenyatta University, Nairobi.

Winpenny, J., Heinz, I., and Koo-Oshima, S. (2010). The wealth of waste: The economics of wastewater use in agriculture. FAO Water Report No. 35. Rome

Wuensch, K. L. (2014). Binary logistic regression with SPSS. [Online]. Available at: $\mathrm{http}: / /$ core.ecu.edu/psyc/wuenschk/spss/logistic.sav (Accessed: 15 November 2019)

[WWAP] United Nations World Water Assessment Programme (2017). Wastewater: The Untapped Resource. The United Nations World Water Development Report 2017. Paris, UNESCO. 
Appendices

Appendix A: Categorical Variables Coding Used in Multivariate Logistic Regression

\begin{tabular}{|c|c|c|c|c|c|c|c|}
\hline Variable & Category & $\begin{array}{l}\text { Variable } \\
\text { code }\end{array}$ & Frequency & Variable & Category & $\begin{array}{l}\text { Variable } \\
\text { code }\end{array}$ & Frequency \\
\hline \multirow[t]{8}{*}{ profession } & $\begin{array}{l}\text { Business \& } \\
\text { related }\end{array}$ & Reference & 32 & \multirow{4}{*}{$\begin{array}{l}\text { Knowledge of } \\
\text { use of TWW } \\
\text { in Ruai }\end{array}$} & I know a lot & Reference & 249 \\
\hline & Farming & Dummy 1 & 53 & & I know a little & Dummy 1 & 82 \\
\hline & $\begin{array}{l}\text { Engineering \& } \\
\text { related }\end{array}$ & Dummy 2 & 24 & & $\begin{array}{l}\text { I have only heard } \\
\text { of it being used }\end{array}$ & Dummy 2 & 22 \\
\hline & Vocational & Dummy 3 & 11 & & I have no idea & Dummy 3 & 1 \\
\hline & Hospitality & Dummy 4 & 26 & \multirow{3}{*}{$\begin{array}{l}\text { Support use } \\
\text { of TWW }\end{array}$} & yes & Reference & 312 \\
\hline & Transport & Dummy 5 & 11 & & neutral & Dummy 1 & 24 \\
\hline & Teaching & Dummy 6 & 9 & & no & Dummy 2 & 18 \\
\hline & $\begin{array}{l}\text { none \& no } \\
\text { response }\end{array}$ & Dummy 7 & 188 & \multirow{3}{*}{$\begin{array}{l}\text { Permission } \\
\text { given to use } \\
\text { TWW }\end{array}$} & yes & Reference & 59 \\
\hline \multirow[t]{8}{*}{$\begin{array}{l}\text { Main } \\
\text { Occupation }\end{array}$} & $\begin{array}{l}\text { Formal / } \\
\text { salaried } \\
\text { employment }\end{array}$ & Reference & 44 & & no & Dummy 1 & 160 \\
\hline & farmer & Dummy 1 & 104 & & I don't know & Dummy 2 & 135 \\
\hline & business & Dummy 2 & 76 & \multirow{3}{*}{$\begin{array}{l}\text { Willingness } \\
\text { to use TWW }\end{array}$} & yes & Reference & 286 \\
\hline & transport & Dummy 3 & 20 & & neutral & Dummy 1 & 19 \\
\hline & casual labour & Dummy 4 & 55 & & no & Dummy 2 & 49 \\
\hline & grocery vendor & Dummy 5 & 11 & \multirow{3}{*}{$\begin{array}{l}\text { Knowledge of } \\
\text { Regulating } \\
\text { organization }\end{array}$} & yes & Reference & 223 \\
\hline & $\begin{array}{l}\text { Vocational } \\
\text { (masonry, } \\
\text { carpentry, } \\
\text { mechanic) }\end{array}$ & Dummy 6 & 39 & & no & Dummy 1 & 52 \\
\hline & other & Dummy 7 & 5 & & I don't know & Dummy 2 & 79 \\
\hline \multirow{5}{*}{$\begin{array}{l}\text { Education } \\
\text { level }\end{array}$} & primary school & Reference & 131 & \multirow{2}{*}{$\begin{array}{l}\text { TWW } \\
\text { reliable }\end{array}$} & no & Dummy 1 & 32 \\
\hline & $\begin{array}{l}\text { secondary } \\
\text { school }\end{array}$ & Dummy 1 & 127 & & yes & Reference & 322 \\
\hline & tertiary & Dummy 2 & 58 & \multirow{2}{*}{$\begin{array}{l}\text { Dependency } \\
\text { on TWW }\end{array}$} & no & Dummy 1 & 189 \\
\hline & university & Dummy 3 & 19 & & yes & Reference & 165 \\
\hline & other & Dummy 4 & 19 & \multirow[t]{2}{*}{ gender } & female & Dummy 1 & 159 \\
\hline \multirow{2}{*}{$\begin{array}{l}\text { TWW } \\
\text { Accessible }\end{array}$} & no & Dummy 1 & 40 & & male & Reference & 195 \\
\hline & yes & Reference & 314 & & & & \\
\hline
\end{tabular}

Appendix B:

Table B1: Results of Omnibus Tests of Model Coefficients with Predictors

\begin{tabular}{|c|c|c|c|c|c|c|c|c|c|}
\hline & & Chi-square & df & Sig. & & & Chi-square & df & Sig. \\
\hline \multirow{3}{*}{ Step 1} & Step & 326.500 & 33 & .000 & Step 5 & Model & 319.586 & 19 & .000 \\
\hline & Block & 326.500 & 33 & .000 & \multirow{3}{*}{ Step 6} & Step & -1.993 & 1 & .158 \\
\hline & Model & 326.500 & 33 & .000 & & Block & 317.593 & 18 & .000 \\
\hline \multirow{3}{*}{ Step 2} & Step & -.037 & 2 & .982 & & Model & 317.593 & 18 & .000 \\
\hline & Block & 326.463 & 31 & .000 & \multirow{3}{*}{ Step 7} & Step & -2.800 & 3 & .424 \\
\hline & Model & 326.463 & 31 & .000 & & Block & 314.793 & 15 & .000 \\
\hline \multirow{3}{*}{ Step 3} & Step & -1.386 & 4 & .847 & & Model & 314.793 & 15 & .000 \\
\hline & Block & 325.078 & 27 & .000 & \multirow{3}{*}{ Step 8} & Step & -4.322 & 2 & .115 \\
\hline & Model & 325.078 & 27 & .000 & & Block & 310.471 & 13 & .000 \\
\hline \multirow{3}{*}{ Step 4} & Step & -4.971 & 7 & .663 & & Model & 310.471 & 13 & .000 \\
\hline & Block & 320.106 & 20 & .000 & \multirow{3}{*}{ Step 9} & Step & -4.407 & 2 & .110 \\
\hline & Model & 320.106 & 20 & .000 & & Block & 306.064 & 11 & .000 \\
\hline \multirow{2}{*}{ Step 5} & Step & -.521 & 1 & .471 & & Model & 306.064 & 11 & .000 \\
\hline & Block & 319.586 & 19 & .000 & & & & & \\
\hline
\end{tabular}


Table B1: Logistic Regression Model Summary

\begin{tabular}{|c|c|c|c|}
\hline \multicolumn{5}{|c|}{-2 Log likelihood } & Cox \& Snell R Square & Nagelkerke R Square \\
\hline 1 & 134.438 & .602 & .827 \\
\hline 2 & 134.474 & .602 & .827 \\
\hline 3 & 135.860 & .601 & .825 \\
\hline 4 & 140.831 & .595 & .817 \\
\hline 5 & 141.352 & .595 & .817 \\
\hline 6 & 143.345 & .592 & .814 \\
\hline 7 & 146.144 & .589 & .809 \\
\hline 8 & 150.467 & .584 & .802 \\
\hline 9 & 154.874 & .579 & .795 \\
\hline
\end{tabular}

Table B2: Variables Removed Stepwise in the Backward Stepwise Logistic Regression

\begin{tabular}{|l|l|c|c|c|}
\hline Step & Variable removed & score & df & Sig. \\
\hline 2 & Permission given to use TWW & 0.036 & 2 & .982 \\
\hline 3 & Education level of respondent & 1.203 & 4 & .878 \\
\hline 4 & Profession for the respondent & 5.330 & 7 & .620 \\
\hline 5 & TWW is Reliable (1) & 0.493 & 1 & .483 \\
\hline 6 & TWW is accessible(1) & 1.852 & 1 & .174 \\
\hline 7 & Knowledge of use of TWW & 2.440 & 3 & .486 \\
\hline 8 & Willingness to use TWW & 4.761 & 2 & .093 \\
\hline 9 & Support for the use of TWW & 4.347 & 2 & .114 \\
\hline \multicolumn{2}{|}{ Overall } & $\mathbf{2 0 . 4 6 2}$ & $\mathbf{2 2}$ & .556 \\
\hline
\end{tabular}

